\title{
The effects of chronic long-term intermittent hypobaric hypoxia on blood rheology parameters
}

\author{
Nermin Yelmen ${ }^{1}$, Semra Ozdemir ${ }^{2}$, Ibrahim Guner ${ }^{1}$, Selmin Toplan², Gulderen Sahin ${ }^{1}$, \\ Onur M. Yaman ${ }^{1}$ and Sevtap Sipahi ${ }^{3}$
}

${ }^{1}$ Department of Physiology, Cerrahpasa Medical Faculty, Istanbul University, Istanbul, Turkey

${ }^{2}$ Department of Biophysics, Cerrahpasa Medical Faculty, Istanbul University, Istanbul, Turkey

${ }^{3}$ Department of Internal Medicine, Cerrahpasa Medical Faculty, Istanbul University, Istanbul, Turkey

\begin{abstract}
The effect of chronic long-term intermittent hypobaric hypoxia (CLTIHH) on blood rheology is not completely investigated. We designed this study to determine the effect of CLTIHH on blood rheology parameters. Present study was performed in 16 male Spraque-Dawley rats that divided into CLTIHH and Control groups. To obtain CLTIHH, rats were placed in a hypobaric chamber ( $430 \mathrm{mmHg}$; 5 hours/day, 5 days/week, 5 weeks). The control rats stayed in the same environment as the CLTIHH rats but they breathed room air. In the blood samples aspirated from the heart, hematocrit, whole blood viscosity, plasma viscosity, plasma fibrinogen concentration, erythrocyte rigidity index and oxygen delivery index were determined. The whole blood viscosity, plasma viscosity, hematocrit and fibrinogen concentration values in the CLTIHH group were found to be higher than those of the control group. However, no significant difference was found in erythrocyte rigidity index and oxygen delivery index between the groups. Our results suggested that CLTIHH elevated whole blood viscosity by increasing plasma viscosity, fibrinogen concentration and hematocrit value without effecting the erythrocyte deformability. Hence, CLTIHH that may occur in intermittent high altitude exposure and some severe obstructive sleep apnea (OSA) patients may be responsible for hemorheologic changes in those subjects.
\end{abstract}

Key words: Chronic long-term intermittent hypoxia — Blood viscosity — Fibrinogen - Erythrocyte deformability

\begin{abstract}
Abbreviations: AHI, apnea hypopnea index; CLTIHH, chronic long term hypobaric hypoxia; CRP, $\mathrm{C}$ reactive protein; Hct, hematocrit; HIF-1, hypoxia inducible factor -1; IH, intermittent hypoxia; ODI, oxygen delivery index; OSA, obstructive sleep apnea; RBC, red blood cell; ROS, reactive oxygen species; VEGF, vascular endothelial growth factor.
\end{abstract}

\section{Introduction}

Hypoxia is one of the most frequent stressing factors encountered in both health and disease and it is often implied as the common cause of tissue and cell injury. However, recent studies reveal that the effects of hypoxia on the body can vary depending on the duration, severity and frequency

Correspondence to: NerminYelmen, Department of Physiology, Cerrahpasa Medical Faculty, Istanbul University, 34098-Fatih, Istanbul, Turkey

E-mail: nermink@istanbul.edu.tr of the hypoxic exposure (Neubauer 2001). Individuals may be exposed to acute, chronic or intermittent hypoxia during their lives. The effects of acute and chronic hypoxia have been assessed for long years. Although intermittent hypoxia is the most common pattern of hypoxic exposure in humans, studies on this issue have just started in the recent years. Intermittent hypoxia (IH) is defined as repeated episodes of hypoxia interspersed with normoxic breathing (Neubauer 2001). IH may be observed in physiological and pathophysiological conditions such as during severe exercise (Dempsey et al. 1984), air travels (Cottrell 1988), exposure to altitude (Hurtado 1960), during sleep in neonates (Thach 1985) and 
obstructive sleep apnea (OSA) and various respiratory diseases (McNicholas 1990). Hypertension, myocardial infarction and stroke are common cardiovascular complications in OSA patients (Roland von Kanel and Dimsdale 2003; Steiner et al. 2005; McNicholas and Bonsignore 2007). In addition, cardiovascular complications commonly occur during morning hours (Kelly-Hayes et al. 1995; Muller 1999). For this reason a relation between cardiovascular events and nocturnal intermittent hypoxia exposure is possible but the mechanism is not clearly understood. The pathophysiologic mechanisms of these events may be related with the rheologic properties of blood. Hemorheology is concerned with the flow properties of cellular and plasmatic components of blood. The resistance of blood to flow is known as blood viscosity. Blood viscosity is determined by hematocrit, plasma viscosity, erythrocyte aggregation and deformability (Stoltz et al. 1999). Furthermore, changes in blood viscosity and its components have been reported to be related to myocardial infarction and stroke (Tozzi-Ciancarelli et al. 1993; Szapary et al. 2004). It has been shown that chronic hypoxia elevates hemorheological factors such as blood viscosity and fibrinogen (Nakanishi et al. 1999) but the effect of chronic intermittent hypoxia on these blood rheology parameters is not clear. A few studies in this subject have been carried out in patients with OSA and it is difficult to define whether chronic intermittent hypoxia is responsible for the rheologic properties of blood of these patients. Because it is also possible that conditions such as age, obesity, hypertension, etc., may have influence on hemorheology. Exposure to intermittent hypoxia may be associated with OSA severity. It is well known that apnea/hypopnea index and the duration of apneic periods are key indicators for determining the severity of OSA. Severe OSA patients may suffer increased number and/or durations of apneic periods. In this case severe OSA patients may be hypoxic during the night because their blood gasses cannot be regulated properly (Kessler 1996; Schulz 2002). It is suggested that frequent repeated apneic periods with time may cause in a blunted chemosensitivity and this state may lead to hypoxia by reducing the hypoxic and hypercapnic ventilatory responses in severe OSA patients in the nighttime (Kessler 1996). In addition, repeated apneic periods may causes hypoxia by progressively reducing lung volume or widening alveolar-arterial $\mathrm{O}_{2}$ gradient (Sands 2010). Therefore the chronic long term hypobaric hypoxia (CLTIHH) protocol we applied and the conditions of some severe OSA patients (hypoxic during nighttime) may be considered resembling.

Also exposure to chronic long-term intermittent hypoxia may occur in repeated high altitude travels. That's why we focused on the CLTIHH that is often encountered when repeated exposure to high altitude is followed by returning to the sea level.

The present study was aimed at understanding the effect of CLTIHH on hemorheological parameters in rats.
The parameters include hematocrit (Hct), whole blood viscosity, erythrocyte deformability, plasma viscosity, plasma fibrinogen concentration and oxygen delivery index (ODI).

\section{Materials and Methods}

All experimental protocols were performed in accordance with the National Institutes of Health guidelines and the approval of the Istanbul University Animal Care and Use Ethics Committee.

\section{Animals and induction of CLTIHH}

In this study, 16 adult male Spraque-Dawley rats weighing $220-250 \mathrm{~g}$ were used. The rats were divided into two groups: control $(n=8)$ and CLTIHH $(n=8)$. To obtain CLTIHH, rats were placed in a hypobaric chamber at barometric pressure of $430 \mathrm{mmHg}$, corresponding to an altitude of 4500 $\mathrm{m}$. The temperature of the chamber was kept at $28^{\circ} \mathrm{C}$ with $12 \mathrm{~h}$ light and dark cycles. The animals were kept at this barometric pressure 5 h/day ( 9 a.m. -2 p.m.), 5 days/week for 5 weeks (Guner et al. 2007). The control rats stayed in the same environment as the CLTIHH rats with access to food and water ad libitum, except that they breathed normal room air. At the end of the CLTIHH exposure both group of animals were anesthetized by injection of intraperitoneal sodium pentobarbital ( $35 \mathrm{mg} / \mathrm{kg}$ ). Then, the syringe needle was inserted just below the xyphoid cartilage and slightly to the left of midline of the rats.The blood samples of both groups were carefully aspirated from the heart into disposable syringe anticoagulated with EDTA at the end of the 5-week CLTIHH period.

\section{Blood rheology measurements}

In the blood samples, Hct, plasma fibrinogen concentration, blood viscosity $\left(\eta_{b}\right)$, plasma viscosity $\left(\eta_{p}\right)$, corrected viscosity, relative viscosity $\left(\eta_{\mathrm{r}}\right)$, erythrocyte (red blood cells, $\mathrm{RBC}$ ) rigidity index and ODI were determined.

Hematocrit was determined after centrifugation in a capillary hematocrit centrifuge at 10,000 rpm for $5 \mathrm{~min}$. Blood viscosity was measured for native hematocrit and for a standard hematocrit of $45 \%$. Measurements of blood viscosity and plasma viscosity were performed with Harkness viscometer (Coulter Electronics Ltd., Ser. No: 6083, England) at high shear rate $\left(>300 \mathrm{~s}^{-1}\right)$ and evaluated in a relation to distilled water at $37^{\circ} \mathrm{C}$ (Bauer 1970). Value of $\eta_{b}$ at corrected $\operatorname{Hct}(45 \%)\left(\eta_{\mathrm{b} 45}\right)$ was calculated according to the following equation (Quemeda 1978):

$$
\eta_{b_{45}}=\eta_{p} \cdot\left(1-\frac{1}{2} \cdot k \cdot \mathrm{Hct}\right)^{-2}
$$


Relative blood viscosity $\left(\eta_{\mathrm{b}} / \eta_{\mathrm{p}}\right)$ was measured and the values of Hct $/ \eta_{b}$ ratio, ODI to tissues, were calculated (Stoltz et al.1991). Fibrinogen was measured according to the Ratnoff and Menzie method in spectrophotometer (UV-160 A Shimadzu) at $520 \mathrm{~nm}$ (Ratnoffand Menzie 1951). The RBC rigidity index (Tk) was calculated according to the following equation (Dintenfass 1985):

$$
\mathrm{Tk}=\frac{\eta_{r}{ }^{0.4}-1}{\eta_{r}{ }^{0.4} \cdot \mathrm{Hct}}
$$

The ability of RBCs to deform was represented as a RBC rigidity index, which is the inverse value of the RBC deformability. An increase in the rigidity index signifies a decrease in the RBC deformability.

\section{Statistical analysis}

Measurements are presented as mean \pm SD. Statistical significance of the differences between control and CLTIHH groups was determined by nonparametric Mann-Whitney $\mathrm{U}$ test. Data analyses were performed using SPSS (version 13.0, SPSS Inc., Chicago, USA), and significance was set at $p<0.05$ for all calculations.

\section{Results}

The measured and calculated hemorheological parameters of the control and CLTIHH group are compared in Table 1. The hematocrit, whole blood viscosity and relative blood viscosity value in CLTIHH group was found to be significantly higher $(p<0.01)$ than that of control group (Fig. 1, 3B and Table 1, respectively). When the plasma viscosity of CLTIHH group and control group were compared, plasma viscosity values of the CLTIHH group were found to be significantly higher

Table 1. Hemorheological parameters of control and CLTIHH group

\begin{tabular}{lcc}
\hline Parameters & $\begin{array}{c}\text { Control } \\
(n=8)\end{array}$ & $\begin{array}{c}\text { CLTIHH } \\
(n=8)\end{array}$ \\
\hline Hematocrit (\%) & $42.50 \pm 2.67$ & $47.50 \pm 1.60^{* *}$ \\
Fibrinogen (mg/dl) & $178.75 \pm 14.33$ & $205.00 \pm 17.73^{* *}$ \\
Plasma viscosity (mPa.s) & $1.00 \pm 0.02$ & $1.03 \pm 0.03^{*}$ \\
Whole blood viscosity (mPa.s) $^{*}$ & $2.99 \pm 0.53$ & $3.77 \pm 0.11^{* *}$ \\
Corrected viscosity $^{\mathrm{a}}$ (mPa.s) & $2.98 \pm 0.53$ & $3.75 \pm 0.11^{* *}$ \\
Relative viscosity (mPa.s) & $2.97 \pm 0.49$ & $3.66 \pm 0.16^{* *}$ \\
RBC rigidity index & $0.82 \pm 0.11$ & $0.85 \pm 0.04$ \\
ODI & $14.63 \pm 2.83$ & $12.59 \pm 0.72$ \\
\hline
\end{tabular}

${ }^{a}$ blood viscosity at corrected $\operatorname{Hct}(45 \%)$; CLTIHH, long-term intermittent hypobaric hypoxia; RBC, red blood cell; ODI, oxygen delivery index. Values are mean $\pm \mathrm{SD} ;{ }^{*} p<0.05,{ }^{* *} p<0.01$ vs. control group.

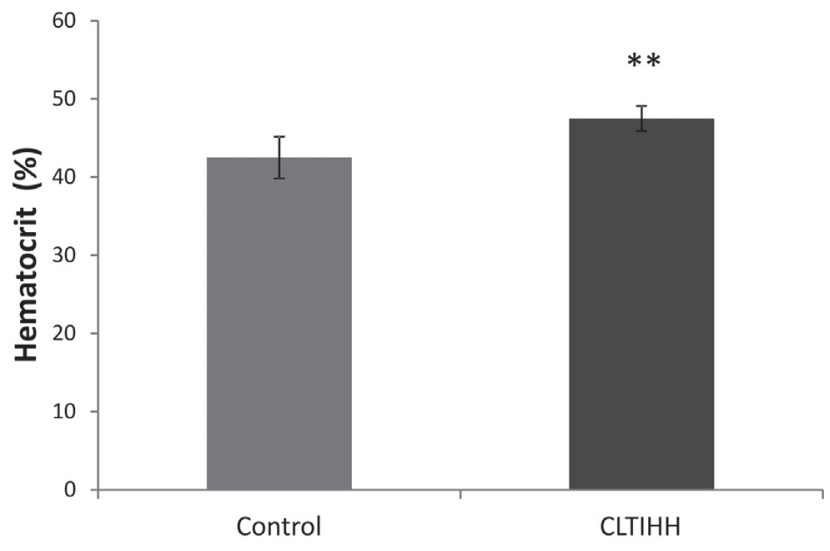

Figure 1. The changes of the hematocrit values in control group and animals treated with chronic long-term intermittent hypobaric hypoxia (CLTIHH). ${ }^{* *} p<0.01$ vs. control group.

( $p<0.05$; Fig. 3A). One of the most important determining factor for plasma viscosity - fibrinogen was found higher in CLTIHH group compared to control group ( $p<0.01 ;$ Fig. 2 ). On the other hand, we found no significant changes in RBC rigidity index values which indicates erythrocyte deformability between the experimental and control groups (Table 1). At the same time ODI value has been determined to define the effect of exposure to CLTIHH on oxygen distribution among tissues. No significant changes in ODI have been observed in both groups (Table 1).

\section{Discussion}

Chronic intermittent hypoxia exposure is a common and one of the most frequent stressing factors in humans. On the other hand, OSA is an important and common disease that is also the predominant pathologic cause of chronic

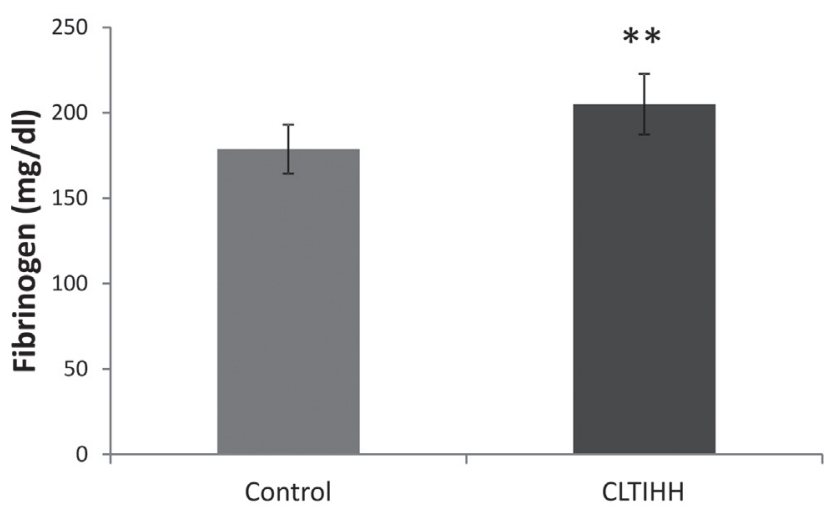

Figure 2. The changes of the fibrinogen values in control and CLTIHH groups. ${ }^{* *} p<0.01 v s$. control group. 
intermittent hypoxia. In patients with OSA, cardiovascular complications are common. Although the pathogenesis of the disease is not clear, those complications may depend on the severity of the nocturnal apnea periods causing exposure to intermittent hypoxia. High incidence of cardiovascular complications taking place in the morning hours is a supportive fact (Dikmenoglu et al. 2006; Kasasbeh et al. 2006). Taking these into consideration, to investigate the effects of CLTIHH on rheological properties of blood and plasmawe performed a CLTIHH model in rats.

Hemorheology is an important subject which studies the rheological properties of blood and blood cells. Major determinants of whole-blood viscosity are hematocrit, plasma viscosity and fibrinogen level and the properties of red cells including erythrocyte aggregation and deformability (Goldsmith and Turitto 1986; Dutta and Tarbell 1996). Several prospective trials confirmed that the increased whole blood viscosity is a major risk factor for ischemic heart disease and stroke (Suarez et al. 1996; Lowe et al. 1997; Lee et al. 1998; Ramping 2008).
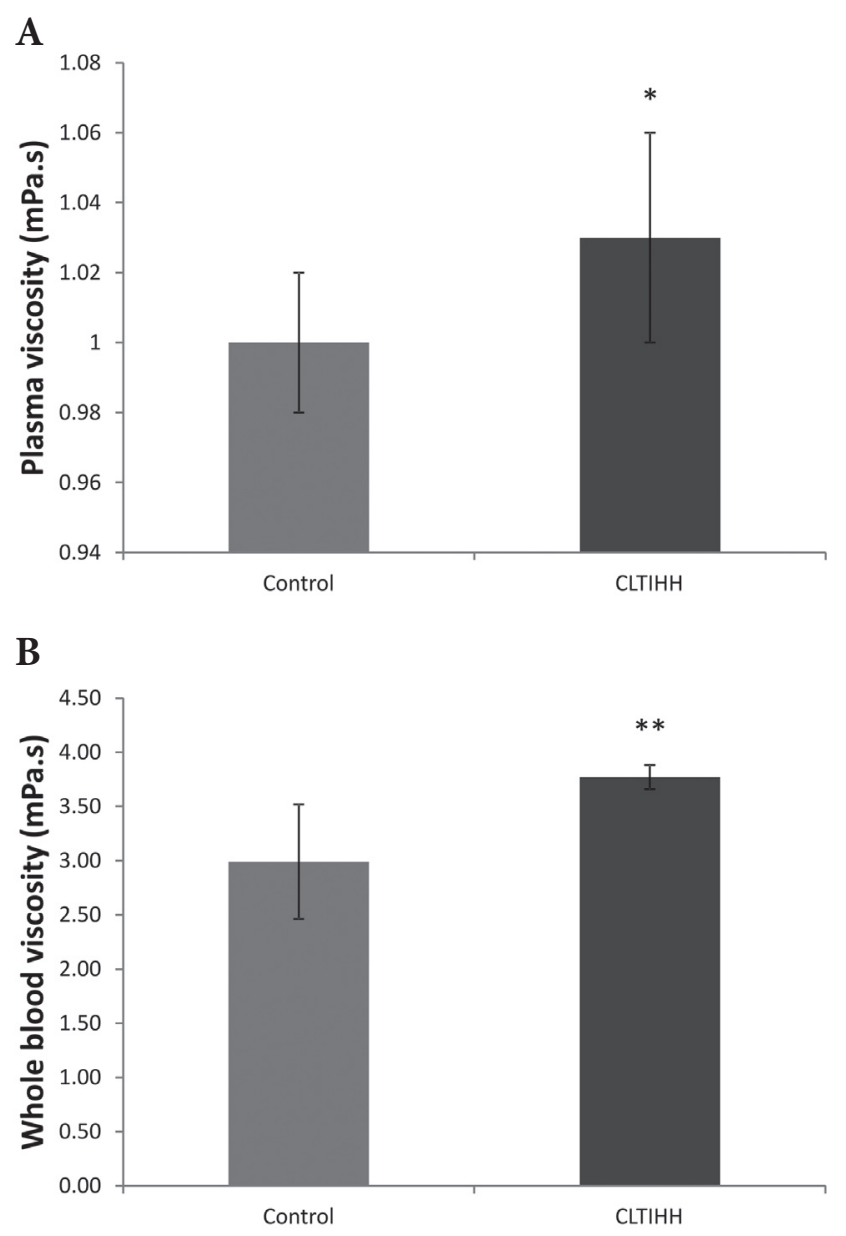

Figure 3. The changes of plasma viscosity (A) and whole blood viscosity (B) values in control and CLTIHH groups. ${ }^{\star} p<0.05$, ${ }^{* *}$ $p<0.01$ vs. control group.
In the present study, we have observed an increase in whole blood viscosity value in CLTIHH exposed rats (Table 1). The blood viscosity determination was performed at high shear rate $\left(>300 \mathrm{~s}^{-1}\right)$. It is known that erythrocytes tend to aggregate with lower velocities of circulating blood (Hardeman 1998), and erythrocyte aggregation is one of the determining factors of the increase in blood viscosity. This increase in blood viscosity is found at low shear rates. Higher shear rates, as observed in larger blood vessels and also in a large portion of small vessels, can reach a shear stress in the order of several hundred reciprocal seconds. In this case, the viscosity is considerably lower than in the low flow states. Therefore, the measurements of blood viscosity give different values, depending on the flow conditions of the blood (Hardeman 1998; Toplan 2004). In the present study high blood viscosity was found in the CLTIHH exposed rats compared to the control rats at high shear rate $\left(>300 \mathrm{~s}^{-1}\right)$. High blood viscosity can slow-down blood flow.It is well known that proper blood circulation is necessary to ensure the nutrient transport and metabolite exchange between blood and the tissues. The adequate blood flow depends on suitable blood viscosity and fluidity. In our study, this increased whole blood viscosity indicates that the chronic long-term intermittent hypoxia is a potential cardiovascular risk factor. The studies about the effects of chronic intermittent hypoxia on blood rheology are limited and focused on OSA patients. As relevant with this subject, Chin et al. (1996) and Tazbirek et al. (2009) reported increased hematocrit and whole blood viscosity values in patients with OSA. In contrast, another study pointed out that experimental chronic intermittent hypoxia had no effect on whole blood viscosity inspite of the elevated hematocrit values (Esteva et al. 2009). Blood is a unique fluid in that it exhibits nonNewtonian characteristics, and its viscosity is dependent on shear rate. Major determinants of whole-blood viscosity are temperature, hematocrit, plasma viscosity, and red cell aggregation and red cell deformation under conditions of low and high shear (Slyper 2005). As is known hematocrit is primary factor that determine whole blood viscosity. In this study we have observed a moderate increase in hematocrit value in CLTIHH exposed rats (Table 1). Hypoxic effects on hematocrit are heavily dependent on the duration and intensity of the hypoxic stimulus (Schimidt 2002). Therefore, the intensity, frequency and duration of intermittent hypoxia cycles are likely the major determinants of erythropoiesis and hematocrit. The studies in severe OSA patients showed a moderate increase in hematocrit value (Hoffstein et al. 1994; Choi et al. 2006), which also supports our findings. In our study we set the hematocrit value to $45 \%$ and evaluated the viscosity value over it. According to our results, the corrected viscosity value (Hct 45\%) in CLTIHH group was found to be significantly higher $(p<0.01)$ than that of control group (Table 1). Our CLTIHH protocol suggested 
that the hematocrit value is effective in the increase of whole blood viscosity.

Plasma viscosity is another important determinant of whole blood viscosity. The viscosity of plasma depends on its macromolecular content, the plasma proteins in particular. Among the plasma proteins, fibrinogen is the one that affects plasma viscosity the most. Although fibrinogen constitutes a very small portion of the plasma proteins, its molecular weight, rigidity, and asymmetrical shape makes it an important determinant (Harkness 1971; Lowe 1994).

When the plasma viscosity and the fibrinogen concentrations values in the CLTIHH group were compared with those of the control group, both plasma viscosity and fibrinogen concentration values of the CLTIHH group were found to be significantly higher than those of control group (Table 1). The elevation of plasma viscosity may depend on the increase in fibrinogen concentration. Steiner et al. (2005) have reported that the patients with OSA have elevated morning fibrinogen levels and a higher plasma viscosity, which correlate positively with indices of sleep apnea severity. In addition, Dikmenoglu et al. (2006) have observed that plasma viscosity is high both in the morning and in the evening in severe obstructive sleep apnea syndrome patients. In both studies the researchers showed that low nocturnal $\mathrm{O}_{2}$ saturation is responsible for the increase in plasma viscosity. On the other hand, it has been shown that plasma fibrinogen levels rise as a result of decreased nocturnal $\mathrm{O}_{2}$ saturation (Steiner et al.2005) and/or increased apnoea-hypopnea index (AHI) taken as a OSA intensity marker (Schulz 2002; Steiner 2005; Dikmenoglu 2006). According to those findings we can assume that hypoxia is an important indicator of OSA intensity. We believe that our findings of increased plasma viscosity and fibrinogen levels are related to thechronic long-term intermittent hypoxia so we believe our findings may support Steiner's and Dikmenoglu's findings.

In contrast, Esteva et al. (2009) showed a decrease in plasma viscosity on rats exposed to chronic intermittent hypobaric hypoxia (22 days, $4 \mathrm{~h}$ /day) simulating $5000 \mathrm{~m}$ altitude. They have stated that the decrease in plasma viscosity could be interpreted as a compensatory response, which reduced the effect of increased erythrocyte mass volume on whole-blood viscosity.

The contrary findings about plasma viscosity may vary according to different hypoxia protocols. As is known, intermittent hypoxia can cause harmful or beneficial effects related to its frequency, severity and duration (Neubauer 2001). Fibrinogen has direct effects on the vascular wall and is a prominent acute-phase reactant. In addition, fibrinogen is closely linked to atherosclerosis and prospective epidemiological trials suggest this association represents a major independent cardiovascular risk factor (Ernst 1993).Wessendorf et al. (2000) describe a correlation between fibrinogen and the degree of nocturnal breathing disorder in patients with stroke.

In the present study, we determined an increase in relative blood viscosity values of CLTIHH group compared to the control group's values (Table 1). Those findings showed us that, although chronic intermittent hypobaric hypoxia increased both plasma and blood viscosity, it has a greater effect on blood viscosity. Another important determinant of blood viscosity is erythrocyte deformability. We found out that chronic intermittent hypoxia did not cause a significant change in erythrocyte rigidity index which is an indicator of erythrocyte deformability (Table 1). As is known, the ability for erythrocytes to deform is an important factor in the microcirculation system. Cell deformability is used to characterize the ability of erythrocyte to change their shapes when passing through micro-vessels (Tsukada et al. 2001). We have not run across any article about erythrocyte deformability in chronic intermittent hypobaric hypoxia exposure. While not exactly intermittent, Palareti et al. (1984) demonstrated a reversible effect on red cell filtration duration following exposure to high altitude $(7350 \mathrm{~m})$. On the other hand, studies with OSA patients indicate that erythrocyte deformability is not much effected (Dikmenoglu et al. 2006; Tazbirek et al. 2009).

In the present study, we demonstrated that although CLTIHH caused a significant increase in blood viscosity values compared to control group values, it had no effect on erythrocyte deformability. As is well known, high blood viscosity slows down the blood flow and results in impaired oxygen transport to tissues. Interestingly, ODI is not effected in our CLTIHH group compared to control group (Table 1). This finding indicates that the chronic intermittent hypobaric hypoxia procedure applied by us did not effect oxygen transport.

According to our findings, the chronic long-term intermittent hypobaric hypoxia caused an increase in whole blood viscosity value by increasing hematocrit, plasma viscosity and fibrinogen values in rats. Chronic intermittent hypoxia stimulates production of reactive oxygen species (ROS) and hypoxia inducible factor-1 (HIF-1) (Semenza 2006; Prabhakar 2007). ROS and HIF-1 facilitate the expression of genes that encode proteins like erythropoietin (Garvey 2009), C-reactive protein (CRP), vascular endothelial growth factor (VEGF) and fibrinogen (Foster 2006). In light of these evidences, CLTIHH may cause elevated whole blood viscosity by increasing plasma viscosity, fibrinogen and hematocrit due to stimulation of ROS and HIF-1 production.

Another important determinant of blood viscosity is erythrocyte deformability. We found out that chronic longterm intermittent hypoxia did not cause a significant change in erythrocyte rigidity index. For this reason, we can assume that CLTIHH has no effect on RBC deformability. 
As a result we demonstrated two points: first, CLTIHH such as seen in intermittent high altitude exposure may cause risk factors for cardiovascular diseases by changing blood rheology without effecting the erythrocyte deformability. Second, frequent and/or prolonged nighttime apnea periods causing chronic long term intermittent hypoxia may be held responsible for hemorheologic changes in severe OSA patients.

Acknowledgements. The present study was supported by Scientific Research Projects Coordination Unit of Istanbul University. Project No. BYP-3187.

\section{References}

Bauer J. D. (1970): Numerical evaluation of white blood cells, red cells, and platelets. In: Gradwohl's Clinical Laboratory Methods and Diagnosis. (Eds. S. Frankel, S. Reitman and A. C. Sonnenwirt), pp. 506-508, CV Mosby Co., St Louis

Chin K., Ohi M., Kita H., Noguchi T., Otsuka N., Tsuboi T., Mishima M., Kuno K. (1996): Effects of NCPAP therapy on fibrinogen levels in obstructive sleep apnea syndrome. Am. J. Respir. Crit. Care Med. 153, 1972-1976

Choi J.B., Loredo J.S., Norman D., Mills P. J., Ancoli-Israel S., Ziegler M. G., Dimsdale J. E. (2006): Does obstructive sleep apnea increase hematocrit? Sleep Breath. 10, 155-160 http://dx.doi.org/10.1007/s11325-006-0064-z

Cottrell J. J. (1988): Altitude exposures during aircraft flight. Flying higher. Chest 93, 82-84 http://dx.doi.org/10.1378/chest.93.1.81

Dempsey J. A., Hanson P. G., Henderson K. S. (1984): Exerciseinduced arterial hypoxemia in healthy human subjects at sea level. J. Physiol. 355, 161-175

Dikmenoglu N., Çiftçi B., Ileri E., Guven S. F., Serringec N., Aksoy Y., Ercil D. (2006): Erythrocyte deformability, plasma viscosity and oxidative status in patients with severe obstructive sleep apnea syndrome. Sleep Med. 7, 255-261 http://dx.doi.org/10.1016/j.sleep.2005.12.005

Dintenfass L. (1985): Red cell rigidity, Tk, and filtration. Clin. Hemorheol. Microcirc. 5, 241-244

Dutta A., Tarbell J. M. (1996): Influence of non-Newtonian behavior of blood on flow in an elastic artery model. J. Biomech. Eng. 118, 111-119 http://dx.doi.org/10.1115/1.2795936

Ernst E. (1993): Fibrinogen as a cardiovascular risk factor-interrelationship with infections and inflammation. Eur. Heart J. 14 (Suppl K), 82-87

Esteva S., Panisello P., Torrella J. R., Pagés T., Viscor G. (2009): Blood rheology adjustments in rats after a program of intermittent exposure to hypobaric hypoxia. High Alt. Med. Biol. 10, 275-281 http://dx.doi.org/10.1089/ham.2008.1086

Foster G. E., Poulin M. J., Hanly P. J. (2006): Intermittent hypoxia and vascular function: implications for obstructive sleep apnoea. Exp. Physiol. 92, 51-65 http://dx.doi.org/10.1113/expphysiol.2006.035204
Garvey J. F., Taylor C. T., McNicholas W. T. (2009): Cardiovascular disease in obstructive sleep apnoea syndrome: the role of intermittent hypoxia and inflammation. Eur. Respir. J. 33, 1195-1205 http://dx.doi.org/10.1183/09031936.00111208

Goldsmith H.L., Turitto V. T. (1986): Rheological aspects of thrombosis and haemostatis: basic principles and applications. ICTH-report-subcommittee on rheology of the international committee on thrombosis and haemostatis. Thromb. Haemost. 55, 415-435

Guner I., Yelmen N., Sahin G., Oruc T., Sipahi S., Yaman M. O. (2007): Respiratory alterations due to chronic long-term intermittent hypobaric hypoxia in rabbits: Importance of peripheral chemoreceptors. Arch. Med. Res. 38, 739-745 http://dx.doi.org/10.1016/j.arcmed.2007.04.010

Hardeman M. R., Van der Kleij A. J. (1998): Hypertension, hemorheology and oxygen transport. Clin. Hemorheol. Microcirc. $19,49-54$

Harkness J. (1971): The viscosity of human blood plasma, its measurement in health and disease. Biorheology 8, 171-193

Hoffstein V., Herridge M., Mateika S., Redline S., Strohl K. P. (1994): Hematocrit levels in sleep apnea. Chest 106, 787-791 http://dx.doi.org/10.1378/chest.106.3.787

Hurtado A. (1960): Some clinical aspects of life at high altitude. Ann. Intern. Med. 53, 247-258

Kasasbeh E., Chi D. S., Krishnaswamy G. (2006): Inflammatory aspects of sleep apnea and their cardiovascular consequences. South Med. J. 99, 58-67 http://dx.doi.org/10.1097/01.smj.0000197705.99639.50

Kelly-Hayes M., Wolf P. A., Kase C. S., Brand F. N., McGuirk J. M., D'Agostino R. B. (1995): Temporal patterns of stroke onset. Stroke 26, 1343-1347 http://dx.doi.org/10.1161/01.STR.26.8.1343

Kessler R., Chaouat A., Weitzenblum E., Oswald M., Ehrhart M., Apprilland M., Krieger J. (1996): Pulmonary hypertension in the obstructive sleep apnoea syndrome: prevalence, causes and therapeutic consequences. Eur. Respir. 9, 787-794 http://dx.doi.org/10.1183/09031936.96.09040787

Lee A. J., Mowbray P. I., Lowe G. D. O., Rumley A.,Fowkes F. G., Allan P. L. (1998): Blood viscosity and elevated carotid intimamedia thickness in men and women: the Edinburg artery study. Circulation 97, 1467-1473

Lowe G. D. O. (1994): Blood rheology,haemostasis and vasculardisease. In: Haemostasis and Thrombosis. (Eds. A. L. Bloom, C. D. Forbes, D. P. Thomas and E. G. D. Tuddenham), pp. 1169-1188, Churchill Livingstone, Edinburg

Lowe G. D. O., Lee A. J., Rumley A., Price J. F., Fowkes F. G. (1997): Blood viscosity and risk of cardiovascular events: the Edinburg artery study. Br. J. Haemotol. 96, 168-173 http://dx.doi.org/10.1046/j.1365-2141.1997.8532481.x

McNicholas W. T. (1990): Sleep apnea. J. Ir. Coll. Physicians Surg. 19, 53-56

Mc Nicholas W. T. (2000): Impact of sleep in COPD. Chest 117, $48-53$ http://dx.doi.org/10.1378/chest.117.2_suppl.48S

Mc Nicholas W. T., Bonsignore M.R., and the Management Committee of EU COST ACTION B26. (2007): Sleep apnea as 
an independent risk factor for cardiovascular disease: current evidence, basic mechanism and research priorities. Eur. Resp. J. 29, 156-178 http://dx.doi.org/10.1183/09031936.00027406

Muller J. E. (1999): Circadian variation in cardiovascular events. Am. J. Hypertens. 12, 355-442 http://dx.doi.org/10.1016/S0895-7061(98)00278-7

Nakanishi K., Tajima F., Nakata Y., Osada H., Sugiyama K., Kawai T., Suzuki M., Torikata C. (1999): Hypercoagulable state in a hypobaric, hypoxic environment causes non-bacterial thrombotic endocarditis in rats. J. Pathol. 181, 338-346 http://dx.doi.org/10.1002/(SICI)1096-9896(199703)181:3<338: AID-PATH773>3.0.CO;2-4

Neubauer J. A. (2001): Physiological and patophysiological responses to intermittenthypoxia. J. Appl. Physiol. 90, 1593-1599

Palareti G., Coccheri S., Poggi M., Tricarico M. G., Magelli M., Cavazzuti F. (1984): Changes in the rheologic properties of blood after a high altitude expedition. Angiology 35, $451-458$ http://dx.doi.org/10.1177/000331978403500708

Prabhakar N. R., Dick T. E., Nanduri J., Kumar G. K. (2007): Systemic, cellular and molecular analysis of chemoreflex-mediated sympathoexcitation by chronic intermittent hypoxia. Exp. Physiol. 92, 39-44 http://dx.doi.org/10.1113/expphysiol.2006.036434

Quemeda D. (1978): Rheology of concentrated disperse systems II. A model of non-newtonian shear viscosity in steady flows. Rheol. Acta. 17, 632-642

Ramping M. W. (2008): The great divide: from viscometer to vasculature. Clin. Hemorheol. Microcirc. 39, 9-20

Ratnoff O. D., Menzie C. A. (1951): A new method for the determination of fibrinogen in small samples of plasma. J. Clin. Med. 37, 316-320

Roland von Kanel, Dimsdale J. E. (2003): Hemostatic alterations in patients with obstructive sleep apnea and implications for cardiovascular disease. Chest 124, 1956-1967 http://dx.doi.org/10.1378/chest.124.5.1956

Sands S. A., Edwards B. A., Kelly V. J., Skuza E. M., Davidson M. R., Wilkinson M. H., Berger P. J. (2010): Mechanism underlying accelerated arterial oxygen desaturation during recurrent apnea. Am. J. Respir. Crit. Care Med. 182, 961-969 http://dx.doi.org/10.1164/rccm.201003-0477OC

Schimidt W. (2002): Effects of intermittent exposure to high altitude on blood volume and erythropoietic activity. High Alt. Med. Biol. 3, 167-176 http://dx.doi.org/10.1089/15270290260131902

Schulz R., Hummel C., Heinemann S., Seeger W., Grimminger F. (2002): Serum levels of vascular endothelial growth factor are elevated in patients with obstructive sleep apnea and severe night time hypoxia. Am. J. Respir. Crit. Care Med. 165, $67-70$
Semenza G. L. (2006): Regulation of physiological responses to continuous and intermittent hypoxia by hypoxia-inducible factor 1. Exp. Physiol. 91, 803-806 http://dx.doi.org/10.1113/expphysiol.2006.033498

Slyper A., Le A., Jurva J., Gutterman D. (2005): The influence of lipoproteins on whole blood viscosity at multiple shear rates. Metabolism 54, 764-768 http://dx.doi.org/10.1016/j.metabol.2005.01.018

Steiner S., Jax T., Evers S., Hennersdof M., Schwalen A., Strauer B. E. (2005): Altered blood rheology in obstructive sleep apnea as a mediator of cardiovascular risk. Cardiology 104, 92-96 http://dx.doi.org/10.1159/000086729

Stoltz J. F., Donner M., Muller S., Larcan A. (1991): Hemorheology in clinical practise. Introduction to the notion of hemorhologic profile. J. Mal. Vasc. 16, 261-270

Stoltz J. F., Singh M., Riha P. (1999): Hemorheology in practice. In: Blood Rheology and Measurements, pp. 15-27, IOS Press, Amsterdam, Netherlands

Suarez C., Castillo J., Suarez P., Naveiro J., Lema M. (1996): The prognostic value of analytical hemorheological factors in stroke. Rev. Neurol. 24, 190-192

Szapary L., Horvath B., Marton Z., Alexy T., Demeter N., Szots M., Klabuzai A., Kesmarky G., Juricskay I., Gaal V., Czopf J., Toth K. (2004): Hemorheological disturbances in patients with chronic cerebrovascular diseases. Clin. Hemorheol. Microcirc. 31, 1-9

Tazbirek M., Slowinska L., Skoczynski S., Pierzchala W. (2009): Shortterm continuous positive airway pressure therapy reverses tje pathological influence of obstructive sleep apnea on blood rheology parameters. Clin. Hemorheol. Microcirc. 41, 241-249

Thach B. T. (1985): Sleep apnea in infancy and childhood. Med. Clin. North Am. 69, 1289-1315

Toplan S., Ozcelik D., Gulyasar T., Akyolcu M. C. (2004): Changes in hemorheological parameters due to lead exposure in female rats. J. Trace Elem. Med. Biol. 18, 179-182 http://dx.doi.org/10.1016/j.jtemb.2004.02.006

Tozzi-Ciancarelli M. G., Di Massimo C., Mascioli A., Tozzi E., Gallo P., Fedele F., Dagianti A. (1993): Rheological features of erythrocytes in acute myocardial infarction. Cardioscience $4,231-234$

Tsukada K., Sekizuka E., Oshio C., Minamitani H. (2001): Direct measurement of erythrocyte deformability in diabetes mellitus with a transparent microchannel capillary model and highspeed video camera system. Microvasc. Res. 61, 231-239 http://dx.doi.org/10.1006/mvre.2001.2307

Wessendorf T. E., Thilmann A. F., Wang Yuo-Ming., Schreiber A., Konietzko N., Teschler H. (2000): Fibrinogen levels and obstructive sleep apnea in ischemic stroke. Am. J. Respir. Crit. Care. Med. 162, 2039-2042

Received: March 21, 2011

Final version accepted: July 25, 2011 